\title{
Primazia das convenções internacionais em matéria tributária sobre o Direito interno
}

\section{RESUMO}

\author{
Karla Margarida* \\ karlasantos@uol.com.br
}

O incremento da acumulação de capitais e sua internacionalização, fomentados pelo processo de globalização, permitem que empresas, nações e indivíduos passem a investir em países em que não estejam fisicamente instalados, atribuindo novo perfil à distribuição de capitais e ao poder dela decorrente. Esforços que tenham por fim harmonizar legislações tributárias, além do incremento ao comércio internacional, evitam o surgimento de situações que constituam óbices à realização de investimentos no país, como o problema da dupla tributação. As convenções internacionais em matéria tributária apresentam-se como mecanismos contra a evasão e a fraude tributária internacionais, possibilitando que empresas e indivíduos, por intermédio de planejamento, minimizem os efeitos da bitributação jurídica e econômica.

Palavras-chave: Convenções internacionais; matéria tributária; normas internas.

\section{The primacy of the International Conventions in tax materia about the internal law}

\begin{abstract}
The increase of capital accumulation and its international movements, fomented by the trial of globalization allow that companies, nations and individuals, put in office in countries in which they are not necessarily physically installed, attributing to a new profile to the distribution of capitals and to the power resulting of it. Efforts that finally are going to harmonize tax legislations, besides the development to the international trade, avoid the sprout of situations that constitute obstacles to the achievement of investments in the country, as the problem of the double taxation. The international conventions in tax matter, present temselves as mechanisms against the evasion and international tax fraud, permitting that companies and individuals, through tax planning, minimize the effects of the legal and economic bi-taxation.
\end{abstract}

Key words: International Conventions. Tax matter. Internal norms.

\footnotetext{
* Professora do UniCEUB; procuradora federal; chefe de estudos e pareceres da Procuradoria do CADE; pesquisadora do Grupo Integrado de Pesquisa em Direito Internacional Econômico e Sistemas de Integração.
} 


\section{INTRODUÇÃO}

O processo de globalização teve grande evolução com o incremento de acumulação de capitais e sua internacionalização, possibilitando a empresas, nações e indivíduos investir em países onde não estejam fisicamente instalados, atribuindo novo perfil à distribuição de capitais e ao poder dela decorrente. No que tange às empresas e aos países detentores de nível de renda elevado, pode-se considerar que a concentração de capitais viabiliza a formulação de estudos e cenários econômicos que lhes dão projeções seguras acerca do processo decisório, minimizando os riscos e viabilizando não apenas o acerto mas também a busca de ganhos diferenciais por meio de adequado planejamento tributário.

O Brasil tem-se mostrado partícipe ativo nas negociações que têm por objetivo incrementar o comércio mundial, imprimindo esforços na melhoria de condições de acesso aos mercados, bem como na eliminação progressiva de barreiras impeditivas ao livre comércio de pessoas, bens e capitais. Nesse sentido, ao firmar convenções que contemplem a matéria tributária, o Estado brasileiro mostra preocupação em eliminar situações que constituam óbices à realização de investimentos no país, como o problema da dupla tributação, haja vista que a maior parte dos Estados soberanos utiliza o critério da taxação global da renda (world wide income taxation). Além de constituírem mecanismos contra a evasão e a fraude tributária internacionais, as convenções permitem que seja feito pelas empresas um planejamento tributário, minimizando efeitos da bitributação jurídica e econômica ${ }^{1}$.

A harmonização das legislações dos Estados envolvidos é uma etapa importante no processo de globalização. Qualquer nação que tenha por objetivo incrementar o comércio internacional deve buscar minimizar, quando não eliminar, os efeitos inconvenientes causados pela dupla ou múltipla imposição fiscal.

\footnotetext{
${ }^{1}$ De maneira simples, podemos considerar que há bitributação jurídica quando determinada imposição recai duas vezes sobre a mesma pessoa; a econômica implica a tributação duas vezes de um determinado. Por exemplo, os dividendos distribuídos por determinada empresa podem ter sido tributados na empresa e perante os acionistas beneficiados.
} 
As convenções internacionais ${ }^{2}$ possuem papel importante na dinâmica econômica, também no fluxo de integração de mercados, constituindo mecanismos utilizados para minimizar ou reforçar estruturas já bastante concentradas e permitir a utilização de estruturas nocivas ao comercio internacional, como associações entre as empresas ${ }^{3}$. Podem constituir excelente ferramenta para que esses entes acumulem capital e reforcem suas estratégias nos mercados de atuação, visando sempre auferir lucros maiores ou incrementar suas parcelas de mercado. A matéria tributária pode ser contemplada como objeto principal ou de forma incidental.

Como expressão da soberania estatal, transacionar em matéria tributária não é tarefa fácil em qualquer Estado soberano. No que se refere ao Brasil essa dificuldade é agravada pela discussão da primazia das regras convencionais sobre as normas de direito interno, máxime quando disponham sobre a competência privativa de estados e municípios. A matéria não é pacífica, e uma análise mais apressada pode trazer sérios efeitos para a economia nacional, ao comprometer a eficácia do texto convencional ou limitar sua abrangência.

O presente trabalho pretende examinar a questão da primazia das convenções internacionais em matéria tributária em que a República Federativa do Brasil figura como parte, justificando a necessidade da prevalência do que nelas for disposto como expressão de autolimitações consensuais efetuadas por entes soberanos. A análise do tema tem relevância diante do posicionamento do Brasil em firmar acordos internacionais com diversos países e, principalmente, sob a perspectiva de criação de mercado comum entre Brasil, Argentina, Paraguai e Uruguai.

Até para o sucesso das etapas que precedem a criação de um mercado comum, como as áreas de livre comércio e as zonas aduaneiras, e a prevalência das disposições de convenções internacionais em matéria tributária revelam importância. A análise das correntes que defendem a existência ou não de única ordem jurídica e a análise das disposições sobre o assunto na Constituição Federal e na jurisprudência auxiliam a situar o país diante de suas leis e de sua vontade de incrementar as relações internacionais com outros Estados soberanos.

\footnotetext{
${ }^{2}$ O uso constante de tratados e convenções sugere que os dois termos venham a designar coisas diversas. Historicamente o termo convenção era utilizado em acordos de menor importância. Como nos lembra Rezek, há variantes terminológicas a expressar o conceito, tratando-se, hoje, de expressões sinônimas, apesar de o texto constitucional utilizar a expressão "tratados e convenções” como se houvesse alguma diferenciação. O tratado pode ser conceituado como um acordo formal, regido pelo direito internacional, por meio do qual se exterioriza a vontade de duas ou mais pessoas jurídicas internacionais; é apto a produzir efeitos jurídicos.

${ }^{3}$ Como associações, considerem-se não apenas arranjos societários, como as joint ventures ou as fusões, mas também estruturas ilícitas, como os cartéis internacionais.
} 


\section{CONVENÇÕES INTERNACIONAIS EM MATÉRIA TRIBUTÁRIA}

\subsection{Aspectos históricos}

Há estudos que indicam as primeiras convenções sobre matéria fiscal no final do século XIX ${ }^{4}$. No entanto, apenas no período próximo à $1^{\text {a }}$ Guerra Mundial, os esforços europeus em matéria de convenções tributárias começam a ser mais eficazes. Em 1922, um grupo de especialistas de sete países europeus foi constituído para elaborar projetos de convenções fiscais, sob a égide das Sociedades das Nações. Em outubro de 1928, uma reunião geral de especialistas governamentais adotou duas séries de textos referentes a modelos de convenções: uma destinada a evitar a dupla imposição, notadamente relativa aos impostos diretos e aos direitos de sucessão; outra referente a modelos de convenções bilaterais relacionados à assistência administrativa e à assistência judiciária em matéria de reembolso ${ }^{5}$.

O Conselho da Organização Européia de Cooperação Econômica (OECE), que se transformou na OCDE em 1960, adotou a primeira recomendação acerca de dupla imposição tributária em 25 de fevereiro de 1955. Em 1956, a OCDE criou um comitê fiscal que elaborou o primeiro projeto de convenção em matéria tributária em 1963, o segundo em outubro de 1977 e o terceiro em novembro de 1983, revisado em setembro de $1992^{6}$. Deve-se destacar a importância desses textos, haja vista terem possibilitado a expansão das relações econômicas internacionais e serem utilizados pelos países industrializados, membros da OCDE.

Em 1946, a Organização das Nações Unidas assumiu as funções antes exercidas pela Sociedade das Nações, oportunidade em que foi criado seu comitê fiscal. No entanto, apenas em dezembro de 1979, por força de críticas por parte dos países menos desenvolvidos ao modelo de convenção elaborado pela OCDE, surgiu novo modelo da ONU (UN Model), privilegiando o

\footnotetext{
${ }^{4}$ Nesse sentido, BORRAS, Alegria. La doble imposición: problemas jurídico-internacionales, Madrid: Ministério de Hacienda - Instituto de Estúdios Fiscales, 1974, 107-154, apud. TORRES, Heleno Taveira. Pluritributação internacional sobre as rendas de empresas - tratamento unilateral e bilateral e comunitário. São Paulo: Revista dos Tribunais, 1997, p. 338; Também, XAVIER,Alberto, Direito tributário internacional do Brasil - tributação das operações internacionais. Rio de Janeiro: Forense, p.94.

${ }^{5}$ L'organisation du système fiscal, capitulo2, p. 244., s.ed., s.d. No mesmo sentido, TORRES (op.cit., p. 339) dispõe de forma pormenorizada que a comissão foi elaborada por Bruins (Rotterdam), Einaudi (Turim), Seligman (Colúmbia) e Stamp (Londres), e a reunião concluída no dia 31.10.1928 contou com a presença de representantes de 27 países.

${ }^{6}$ As atualizações não modificaram a redação das cláusulas convencionais, nem tampouco as soluções de fundo sobre as diversas categorias de renda, mas sim os comentários, cujo conteúdo foi ampliado e aprimorado por força das discussões levadas a efeito no comitê fiscal. Nesse sentido, cf. TORRES, Heleno, p. 345, op. cit.
} 
critério da territorialidade, ou seja, dando prevalência à fonte dos rendimentos, em detrimento do princípio da residência. Apesar disso, o fluxo das relações entre os Estados, principalmente por força do poder econômico das nações consideradas mais desenvolvidas, fez prevalecer o modelo da OCDE, a despeito do modelo de convenção elaborado pela ONU.

\subsection{Posição das normas internacionais em face do direito interno}

Ao analisar as convenções internacionais, contemplando matéria tributária, há que se perquirir em qual situação as normas convencionais ganham relevância sobre dispositivos da ordem interna e como as normas internacionais são consideradas pelo ordenamento nacional ${ }^{7}$. As convenções internacionais sobre matéria tributária são firmadas com o fim de eliminar ou, ao menos, atenuar os efeitos causados pela incidência excessiva de tributos, diante da presença de determinados estabelecimentos em mais de um Estado soberano. Além disso, visam favorecer a assistência cooperativa internacional, assegurando maior transparência às firmas com atuação em diversos países em pontos considerados obscuros na análise do texto, fatos que incrementam o comércio internacional, dando maior garantia do tratamento das rendas. No entanto, a aplicabilidade das normas convencionais e seu cotejamento com as normas internas passam a ter reflexos não apenas nas relações internacionais entre os países mas também internamente, ao serem aplicadas e confrontadas com as leis vigentes em cada Estado.

As cláusulas convencionais não podem ferir a soberania técnica dos Estados, que, por sua vez, não podem alegar a existência de óbices técnicos ou econômicos para frustrar a convenção. Por outro lado, não pode a República Federativa do Brasil ficar condicionada à vontade de estados e municípios quando for necessária a celebração de tratados internacionais em matéria tributária. Situações como essas expressam as divergências em torno da primazia das convenções no direito interno, em face do disposto no artigo 98 do Código Tributário Nacional, e a forma como o citado diploma tributário foi recepcionado pelo texto constitucional.

Segundo Torres ${ }^{8}$, as regras convencionais podem ser expressas em três modelos:

\footnotetext{
${ }^{7}$ XAVIER, Alberto. Direito Tributário Internacional do Brasil, 5. ed. Rio de Janeiro: Forense, 1998. p. 102.

${ }^{8}$ TORRES, Heleno. Pluritributação internacional sobre a renda das empresas. São Paulo: Revista dos Tribunais, 1997. p. 389/390.
} 
- O primeiro, com o predomínio do direito interno, destaca que, ao compor parte do direito nacional, a convenção entra, automaticamente, em vigor, sem necessidade de ordem de aplicação ou edição de lei com seu conteúdo.

- O segundo, com predomínio do direito internacional, demonstra a existência de ordem internacional de interesses que prevalece ao ser cotejada com as normas internas.

- Por último, a posição que reflete o monismo moderado admite a equivalência entre as normas internas e internacionais, com a aplicabilidade do princípio lex posterior derogat priori para solução de antinomias.

Nesse sentido, passamos a analisar, de forma breve, as posições externadas nas teorias monista e dualista.

\subsection{Monistas e dualistas}

A incorporação dos tratados internacionais ao direito interno envolve o exame das doutrinas monista e dualista. A questão torna-se importante ao estudar-se a primazia nas normas convencionais sobre as normas de direito interno, especialmente no que se refere à hierarquia entre as normas.

Uma das formas de expressão monista é a capitaneada pela Escola de Viena, que defende o monismo como prioridade do direito internacional. Kelsen, ao formular a Teoria Pura do Direito, enunciando a célebre pirâmide de normas, estabelece que uma norma tem origem e tira a obrigatoriedade da que lhe é imediatamente superior, situando-se no ápice a norma fundamental (grundorm) hipotética. Como destaca Mello, essa fase ficou conhecida como a da livre escolha. Posteriormente, por influência de Alfred Von Verdross, Kelsen passa a considerar a grundnorm como a norma de direito internacional expressa no pacta sunt servanda. A escola realista francesa (Duguit e Politis), em 1927, defende o primado do Direito Internacional com base na noção de soberania, que deve ser compreendida com relatividade e dependente de uma ordem internacional ${ }^{9}$. De forma resumida, portanto, os monistas, baseados em Kelsen, entendem que há unidade entre o ordenamento nacional e internacional. Assim, ao contrair obrigações no plano internacional, o Estado exerce parte de sua soberania.

\footnotetext{
${ }^{9}$ op. cit., p. 111-112.
} 
Xavier $^{10}$ e Mello ${ }^{11}$, ao posicionar-se como monistas, destacam a posição com a primazia do Direto interno. Com raízes no hegelianismo, o monismo considera o Estado como ente soberano, não se sujeitando a nenhum sistema jurídico que não tenha emanado de sua vontade. O Direito internacional tem a obrigatoriedade respeitada por forças das relações que o Estado mantêm no contexto internacional. Conforme destaca Mello ${ }^{12}$, doutrinadores como Wenzel, os irmãos Zorn, Decencière-Ferrandièr e, inicialmente, Verdross, defendiam essa corrente. Autores soviéticos, como Korovin, também declaravam que o direito internacional só teria validade se fosse parte do direito nacional.

Um dos argumentos que refutam a aplicabilidade da corrente monista é que sua aceitação implicaria a violação dos artigos 26 e 27 do Pacto de Viena, no qual o Brasil figura como signatário, por permitir que as partes invoquem disposições do direito interno como justificativa para desobedecer às regras convencionais. Contrapondo-se aos monistas, a teoria dualista, posição resguardada por Heleno Torres $^{13}$, defende a separação entre a ordem internacional e a ordem interna.

Henrich Triepel $^{14}$, precursor deste entendimento, na obra Volkerrecht und Landesrecht, concebe o Direito interno e o Direito internacional como ordens jurídicas distintas. Comparando as ordens jurídicas às retas, estabelece que aquelas podem tocar-se em algum ponto, mas jamais serão secantes, ou seja, são independentes. As relações mantidas na ordem internacional, portanto, são efetuadas entre Estados, enquanto, no âmbito interno, os indivíduos figuram como sujeitos de direitos e obrigações. O Direito interno expressa a vontade de um Estado soberano, enquanto o Direito internacional expressa a vontade de diversos entes soberanos. No que tange à estrutura, o Direito interno está baseado em sistema de subordinação, enquanto a ordem internacional se baseia em sistema de coordenação ${ }^{15}$.

Não há consenso entre os doutrinadores brasileiros acerca da teoria adotada no país. Torres $^{16}$ entende que a teoria adotada na Constituição Federal é a dualista diante do pluralismo

\footnotetext{
${ }^{10}$ XAVIER, Alberto. op. cit., p. 105 e segs.

${ }^{11}$ MELLO, Celso D. de Albuquerque. Curso de Direito Internacional Público. 12. ed. Rio de Janeiro: Renovar, vol. I, 2.000, p. 109.

${ }^{12}$ Ibidem.

13 TORRES, op. cit., p.388.

${ }^{14}$ Triepel apud. MELLO, Celso op. cit., p. 83-84

${ }^{15}$ MELLO, op.cit., p. 109-110.

${ }^{16}$ Op. cit, p. 388.
} 
sistêmico das ordens jurídicas, com fronteiras precisas entre a ordem jurídica interna e a internacional, quer quanto às fronteiras jurídicas, quer quanto aos critérios de validade admitidos.

Valadão $^{17}$ e Grupenmacher ${ }^{18}$ defendem a adoção de sistema misto pelo constituinte nacional, haja vista que, quanto aos direitos e às garantias individuais, com base no que está disposto nos $\S \S 1^{\circ}$ e $2^{\circ}$ do artigo $5^{\circ}$, da Constituição Federal, o sistema é o monista, dispensando a aprovação legislativa. Quando o tratado acarreta encargos ou compromissos gravosos para o patrimônio nacional (artigo 49, I da CF) ao texto constitucional, denota a utilização do posicionamento dualista.

Xavier $^{19}$, ao posicionar-se como monista, tece críticas aos dualistas, considerando essa forma de expressão como resquícios totalitários que poderiam ter sido evitados no texto da Constituição Federal de 1988. Conforme ressaltou o Ministro Celso de Mello, o debate entre monistas e dualistas não é o ponto central para o alcance da solução normativa da incorporação dos tratados internacionais ao direito positivo interno, devendo a solução ser alcançada na Constituição Federal. ${ }^{20}$.

\section{DISPOSIÇÕES CONSTITUCIONAIS E NORMAS CONVENCIONAIS NTERNACIONAIS EM MATÉRIA TRIBUTÁRIA}

Os tratados internacionais refletem situações em que cada um dos membros abre mão de parcela da soberania. Em matéria tributária, devem seguir os mesmos trâmites legais que os demais tratados firmados pelo país. A Constituição Federal, no artigo 21, inciso I estabelece que compete à União manter relações com Estados estrangeiros e participar de organizações internacionais. Assim, pode-se concluir que o texto constitucional permite que a União mantenha relações com Estados estrangeiros e participe de organizações internacionais na qualidade de representante da República Federativa do Brasil, podendo manifestar-se em nome dos estados, dos municípios e do Distrito Federal.

\footnotetext{
${ }^{17}$ VALADÃO, Marcos Aurélio Pereira. Limitações constitucionais ao poder de tributar e tratados internacionais. .Belo Horizonte. Del Rey, 2000, p. 169.

${ }^{18}$ GRUPENMACHER, Betina Treiger. Tratados internacionais em matéria tributária e a ordem interna. São Paulo: Dialética, 1999, p. 72.

${ }^{19}$ XAVIER, op. Cit., p. 104.

${ }^{20}$ Nesse sentido, cf. o voto proferido pelo Ministro Celso de Melo no julgamento da ADIN 1.480-DF.
} 
O artigo 84, inciso VII da Constituição Federal, por sua vez, estabelece a competência privativa do Presidente da República para celebrar tratados, convenções e atos internacionais sujeitos ao referendo do Congresso Nacional. Segundo Xavier, a celebração cabe apenas ao Presidente da República. No entanto, a necessidade de que seja referendado pelo Congresso Nacional, para que ocorra a ratificação por meio de decreto legislativo, mostra a importância do Congresso Nacional em sua realização. Não é forçoso concluir que a participação do Legislativo pode inviabilizar a ratificação de um tratado caso os representantes entendam que represente prejuízos gravosos aos interesses nacionais (artigo 49, I, CF), inclusive ferindo a competência dos entes federados em questões tributárias. No que se refere à divisão de competência em matéria tributária, a Constituição Federal traz uma vedação aos entes federados de legislar sobre normas gerais de direito tributário, diferentemente de outras matérias em que a União pode dispor sobre normas gerais, o que só pode ser feito por intermédio de lei complementar (artigo 146, inciso III, CF), procedimento mais rígido que permite o controle dos tributos instituídos.

A redação do $\S 2^{\circ}$ do artigo $5^{\circ}$ da Constituição Federal dispõe que “os direitos e as garantia expressos nesta Constituição não excluem outros decorrentes do regime e dos princípios por ela adotados, ou dos tratados internacionais em que a República Federativa do Brasil seja parte”. O dispositivo permite que os tratados sejam recebidos na ordem interna com a possibilidade de utilização do sistema de recepção automática plena. Em nome da segurança jurídica e da estabilidade das relações com outras nações, são reconhecidos direitos subjetivos e garantias individuais para os brasileiros e estrangeiros residentes no país, decorrentes de tratados internacionais em que a República seja parte.

De acordo com Xavier ${ }^{21}$, a matéria tributária, por força da redação do artigo 150, caput da Constituição Federal, atinge direitos e garantias, como a liberdade de comércio, a propriedade privada e a vedação de confisco. Mesmo que não se considere a matéria tributária atingir direitos e garantias fundamentais, não se pode negar que o Estado brasileiro, ao assegurar que direitos e garantias decorrentes de textos convencionais dos quais o Brasil seja parte não excluam outros decorrentes dos princípios adotados, denota o ensejo do legislador em atender ao princípio do pacta sunt servanda, prestigiando as normas convencionais.

\footnotetext{
${ }^{21}$ Op. cit., p. 129.
} 
No entanto, entende-se que a opção contida no texto constitucional reflete o dualismo moderado, haja vista que o Poder Legislativo, ao aprovar o texto de um tratado internacional em matéria tributária, por poder refletir encargos ou compromissos gravosos ao patrimônio, autoriza o Presidente da República a ratificá-lo. Há parceria entre o Legislativo e o Executivo. No entanto, concedida a aprovação, não fica o Presidente da República obrigado à ratificação. A palavra final na celebração dos tratados no sistema brasileiro cabe ao chefe do Executivo, constituindo a manifestação do Legislativo como hipótese definitiva caso negue a aprovação do texto.

\section{CRITÉRIOS PARA SOLUÇÃO DE CONFLITOS COM A LEI INTERNA}

Quanto ao ordenamento pátrio, resta claro que a Constituição Federal, por força da disposição dos dispositivos destacados, prepondera em face ao estabelecido em convenções internacionais em matéria tributária (lex superior derrogat legi inferiori), que não são recepcionadas de forma automática, diante da potencialidade de ônus gravosos ao patrimônio nacional. No que tange aos textos convencionais perante as normas infraconstitucionais, é possível afirmar que as disposições prevalecem sobre o que estabelece a lei interna, diante da aplicação do princípio da especialidade (lex specialis derrogat legi generali). Desse modo, o eventual surgimento de normas internas posteriores que trouxessem disposições diferentes às contidas na convenção tributária seriam solucionadas pela aplicação do contido no tratado, em face de sua característica de especialidade, em detrimento da norma tributária interna, marcadamente genérica.

Outro critério que tem sido buscado de forma reiterada na solução de conflitos entre as normas internas e as convencionais tributárias é o do pacta sunt servanda. Embora não haja, no direito brasileiro, dispositivo que o consagre, está implícito em outras normas constitucionais que atribuem primazia às convenções sobre a legislação interna. O posicionamento adotado pelo país nas relações que mantém com outros Estados soberanos mostra o comprometimento com a nova ordem internacional. Não respeitar as convenções internacionais tributárias celebradas com

outros países representa não apenas desrespeito às normas internacionais, mas também o 
posicionamento na contramão do processo de integração de mercados. Como assevera Fraga ${ }^{22}$, "os sentimentos de solidariedade e de interdependência que animam os povos, o reconhecimento da existência da sociedade internacional, além de outros fatores, tornam indiscutível, na consciência jurídica universal, o respeito aos compromissos assumidos”.

\section{O ARTIGO 98 DO CÓDIGO TRIBUTÁRIO NACIONAL E AS DISPOSIÇÕES CONTIDAS EM CONVENÇÕES INTERNACIONAIS EM MATÉRIA TRIBUTÁRIA}

O artigo 98 do CTN estabelece que os tratados e as convenções internacionais revogam ou modificam a legislação tributária interna, devendo ser observados pela (legislação) que lhes sobrevenha. A análise desse dispositivo remete-nos à discussão de monistas versus dualistas. Diante da redação do artigo 146 da Constituição, resta claro que o CTN foi recepcionado como lei complementar ${ }^{23}$.

A lei 5.172/66, ao tratar das normas gerais de Direito Tributário, configura o tratado como fonte de direito. Os dispositivos constitucionais que celebram tratados e a forma de recepção pelo direito nacional estabeleceram regramentos para que fossem introduzidos no ordenamento jurídico. Após a celebração, a aprovação e a ratificação, os tratados que contemplem matéria tributária ingressam no ordenamento jurídico no mesmo nível das normas ordinárias.

Coelho assevera que a Constituição de 1988 reforçou o poder das normas gerais de direito tributário. O artigo 98 do CTN, que foi recebido pelo texto constitucional, demonstra que devem ser prestigiadas as relações internacionais e as obrigações assumidas pelo país.

Como assevera Xavier ${ }^{24}$, houve um equívoco do legislador ao elaborar a redação do artigo 98, pois contempla a revogação de uma norma interna por outra de natureza internacional. Não se trata de ab-rogação, mas sim de derrogação, haja vista que a norma interna permanece válida e eficaz no ordenamento pátrio. A lei interna tem eficácia contida com relação a determinados indivíduos e situações disciplinados pela norma internacional conflitante. Como

\footnotetext{
${ }^{22}$ FRAGA, Mirtô. O conflito entre Tratado Internacional e Norma de Direito Interno. Rio de Janeiro: Forense, 1997. p. 95.

${ }^{23}$ Essa posição é defendida por Heleno Torres em Pluritributação internacional sobre a renda das empresas. São Paulo: Revista dos Tribunais, 1997. p 399 e segs.

${ }^{24}$ Xavier, Alberto; Xavier, Heleno de Araújo Lopes, apud Grupenmacher, op. cit., p. 113.
} 
destaca o autor, a lei interna mantém a eficácia plena fora das hipóteses não contempladas pelo tratado, o que representa limitação de eficácia da norma a situações específicas e delimitadas.

É polêmico o alcance do que dispõe o artigo 98 do CTN. Por meio de leitura mais acurada, verifica-se que a legislação interna a que faz referência deve ser a contida em lei ordinária, e não a reservada à lei complementar, hipótese em que se configuraria inconstitucionalidade do texto convencional. No mesmo sentido, os efeitos alcançados pela convenção internacional também devem ser aqueles abrangidos pela lei ordinária. A redação do artigo 98 do CTN reforça o contido neste diploma de que as regras estabelecidas são disposições gerais de direito tributário.

\section{POSIÇÃO JURISPRUDENCIAL}

Alguns julgados do Supremo Tribunal Federal e do Superior Tribunal de Justiça esclarecem que o entendimento jurisprudencial acerca da aplicabilidade das convenções tributárias internacionais, haja vista a redação do artigo 102, III, b, que estabelece a competência da Corte Maior em julgar, em recurso extraordinário, causa em que a decisão recorrida “declarar a inconstitucionalidade de tratado ou lei federal”, dispõe, no que se refere ao artigo 98 do CTN, a aplicabilidade na solução de antinomias advindas do confronto entre as normas convencionais e as internas.

TRIBUTÁRIO. REGIME INTERNACIONAL. DUPLA TRIBUTAÇÃO. IRRPF. IMPEDIMENTO. ACORDO GATT. BRASIL E SUÉCIA. DIVIDENDOS ENVIADOS A SÓCIO RESIDENTE NO EXTERIOR. ARTIGOS 98 DO CTN, $2^{\circ}$ DA LEI 4.131/62, $3^{\circ}$ DO GATT.

a) Os direitos fundamentais globalizados estão no caminho do impedimento da dupla tributação, condenada por princípios que estão acima da norma constitucional.

b) O Brasil adota para o capital estrangeiro regime de equiparação de tratamento (artigo $2^{\circ}$ da Lei 4131/62, recepcionado pelo artigo 172 da CF), legalmente reconhecido no artigo 150, II, da CF, que, embora se dirija, de modo explícito, à ordem interna, também é dirigido às relações externas.

c) O artigo 98 do CTN permite a distinção entre os chamados tratados-contratos e os tratados-leis. Toda a construção a respeito da prevalência da norma interna com o poder de revogar os tratados, equiparando-os à legislação ordinária, foi feita tendo em vista os designados tratados, contratos, e não os tratados-leis.

d) Sendo o princípio da não-discriminação tributária adotado na ordem interna, deve ser adotado também na ordem internacional, sob pena de desvalorizarmos as relações internacionais e a melhor convivência entre os países. 
e) Há supremacia do princípio da não-discriminação do regime internacional tributário e do artigo $3^{\circ}$ do GATT.

f) Há o recurso especial provido. ${ }^{25}$

TRIBUTÁRIO. ICMS. IMPORTAÇÃO DE BACALHAU - GATT. ALEGADA IMPOSSIBILIDADE DE ISENÇÃO DO ICMS POR MEIO DO TRATADO INTERNACIONAL. SUBSISTÊNCIA DAS SÚMULAS 575/STF, 20/STJ e 71/STJ.

O artigo III do Acordo Geral não concedeu nenhuma espécie de isenção, mas determinou que o tratamento tributário entre o produto nacional e seu respectivo ou similar estrangeiro deve ser isonômico em relação às operações internas. Embora o ICMS seja tributo de competência dos Estados e do Distrito Federal, é lícito à União, por tratado ou convenção internacional, garantir que o produto estrangeiro tenha a mesma tributação do similar nacional.Assim, verifica-se que a Súmula 575 do Supremo Tribunal Federal e as Súmulas 20 e 71 do Superior Tribunal de Justiça continuam com plena força. Há recurso especial provido.

TRIBUTÁRIO E PROCESSUAL CIVIL. AGRAVO REGIMENTAL EM FACE DE DECISÃO QUE DEU PROVIMENTO A RECURSO ESPECIAL. MANDADO DE SEGURANÇA. PRAZO DECADENCIAL. IMPORTAÇÃO DE BACALHAU. ISENÇÃO DE ICMS. ACORDO GATT. SÚMULA N ${ }^{\circ} 71$ DO STJ. INAPLICABILIDADE DA SÚMULA No 126 DO STJ. RECURSO DESPROVIDO.

a) O mandado de segurança, quando presentes os seus requisitos, é meio adequado para o reconhecimento da isenção do ICMS sobre a importação de bacalhau.

b) A fluência do prazo decadencial da ação mandamental é de 120 dias, contados da ocorrência do suporte fático, e não da edição do Convênio.

c) $\mathrm{O}$ fundamento infraconstitucional consubstanciado na incidência de tratado internacional, com força de lei federal, apresenta-se de forma autônoma no deslinde do julgado. Destarte, a Súmula no 126 não implica óbice ao julgamento deste especial.

d) Aplica-se a Súmula $n^{\circ} 71$ do STJ para isentar da cobrança o ICMS na importação do bacalhau da Noruega, país signatário do GATT, assim como o Brasil. Embora seja de competência dos Estados e do Distrito Federal instituir tal tributo, a Lei permite que a União, por tratado ou convenção internacional, garanta que o produto estrangeiro tenha a mesma tributação do similar nacional, devendo ser aplicada.

e) Há agravo regimental desprovido ${ }^{26}$.

25 Resp. 42. 6945/PR, relator Ministro Teori Albino Zavascki. Relator do acordo Ministro José Delgado, $1^{\mathrm{a}}$ Turma, publicado no DJ de 25.08.2004.

${ }^{26}$ AgRg no RESP 205352/RS; AgRg no RESP 1999.0017312-0; Ministra Laurita VAZ, 2 ${ }^{\mathrm{a}}$ Turma, 16.04.2002. DJ 28.04.03, p. 182 
TRIBUTÁRIO. ICMS. IMPORTAÇÃO DE BACALHAU - GATT. ALEGADA IMPOSSIBILIDADE DE ISENÇÃO DO ICMS POR MEIO DO TRATADO INTERNACIONAL, POR CUIDAR DE TRIBUTO ESTADUAL SUBSISTÊNCIA DA SÚMULA $\mathrm{N}^{\circ} 575$ DO SUPREMO TRIBUNAL FEDERAL E DAS SÚMULAS Nº 20 e 71

DO SUPERIOR TRIBUNAL DE JUSTIÇA.

O artigo III do Acordo Geral não concedeu nenhuma espécie de isenção, mas determinou que o tratamento tributário entre o produto nacional e seu respectivo ou similar estrangeiro deve ser isonômico em relação às operações internas. Embora o ICMS seja tributo de competência dos Estados e do Distrito Federal, é lícito à União, por tratado ou convenção internacional, garantir que o produto estrangeiro tenha a mesma tributação do similar nacional.

Como os tratados internacionais têm força de lei federal, nem os regulamentos do ICMS, nem os convênios interestaduais têm poder para revogá-los. Nesse caso, verifica-se que a Súmula 575 do Supremo Tribunal Federal e as Súmulas 20 e 71 do Superior Tribunal de Justiça continuam com plena força. Há agravo regimental a que se nega provimento ${ }^{27}$.

Os julgados colacionados deixam claro que, no entender das cortes nacionais, a Constituição tem prevalência sobre os tratados. Segundo Rezek, não há ordenamento jurídico contemporâneo que dê prevalência aos tratados sobre a Constituição. Diante da diferenciação que há na Carta Magna da recepção aos tratados que contemplem direitos fundamentais e dos que possam gerar prejuízos gravosos ao patrimônio nacional, institui-se parâmetro de aferição de qualidade das leis e dos tratados internacionais, no que se refere tanto ao conteúdo (para não colidir com regras substantivas da Carta) quanto à forma de produção.

Como menciona Borges, não faz mais sentido discutir a inconstitucionalidade do artigo 98 do CTN. Em harmonia com o referido autor, alguns julgados colacionados refletem que a solução para os conflitos entre convenções tributárias e a lei interna, diante da omissão da Constituição, deve ser extraída do próprio sistema e não do artigo 98.

Além disso, os tratados internacionais em matéria tributária, mesmo que recebidos na ordem interna, devem ter assegurada a aplicabilidade, não por força de norma que assim estabeleça, mas pela aplicabilidade do critério da especialidade. Grupenmacher ${ }^{28}$ assevera que o artigo 98 do CTN integra, com outros, texto de lei complementar que tem, por força do que

\footnotetext{
${ }^{27}$ AgRg no AG 438449/RJ, AGRG no AI 20020018720-3; Ministro Franciulli Netto, 2ª Turma, 05.09.2002, DJ 07.04.2003, p. 264

${ }^{28}$ Op. cit,. p. 114.
} 
dispõe o artigo 146 da Constituição Federal, a função primordial de estabelecer normas gerais em matéria tributária, entre as quais se encontram as referentes à interpretação, à vigência e à aplicação da legislação tributária.

A solução não pode ficar restrita ao conceito antigo de soberania, o que implicaria a tomada de posição consistente com a inclusão, na Constituição Federal, de dispositivo que, claramente, atribuísse superioridade ao tratado, não somente em razão do critério da especialidade, como também por representar a sua assinatura e a ratificação compromisso do Estado brasileiro (pacta sunt servanda), cuja observação e cujo respeito concedam a necessária credibilidade e o avanço nas relações internacionais do país. A treaty override, como outros problemas decorrentes de falhas na aplicação das normas convencionais tributárias, não é privilégio do Brasil, pois premidos por circunstâncias que não cabe debater, outros tantos países, caracterizados como desenvolvidos, deixam de lado os tratados já ratificados para dar preferência aos interesses nacionais.

\section{REFERÊNCIAS}

GRUPENMACHER, Betina Treiger. Tratados internacionais em matéria tributária e a ordem interna. São Paulo: Dialética, 1999. p. 72.

MELLO, Celso D. de Albuquerque. Curso de direito internacional público. 12.ed. Rio de Janeiro: Renovar, 2.000. v. 1.

FRAGA, Mirtô. O conflito entre tratado internacional e norma de direito interno. Rio de Janeiro: Forense, 1997.

SUPERIOR TRIBUNAL DE JUSTIÇA.[Home page]. Brasíla, 2005. Disponível em: <http://www.stj.gov.br.> Acesso em: fev. 2005.

TORRES, Heleno Taveira. Pluritributação internacional sobre as rendas de empresas: tratamento unilateral e bilateral e comunitário. São Paulo: Revista dos Tribunais, 1997.

VALADÃO, Marcos Aurélio Pereira. Limitações constitucionais ao poder de tributar e tratados internacionais. Belo Horizonte: Del Rey, 2000. p. 169.

XAVIER, Alberto. Direito tributário internacional do Brasil: tributação das operações internacionais. Rio de Janeiro: Forense. 
Prismas: Direito, Políticas Públicas e Mundialização

http://www.mestrado.uniceub.br/revistamestrado/

Artigo recebido em 29/09/2005 e aceito para publicação em 15/02/2006

A revista Prismas: Direito, Políticas Públicas e Mundialização destina-se à publicação de artigos relacionados com a área jurídica, tem o propósito de difundir as reflexões dos pesquisadores, docentes, discentes, profissionais e estudantes da área de Ciências Jurídicas.

Os artigos são avaliados mediante processo de revisão por pares e deverão contemplar as reflexões que dizem respeito ao estudo do Direito, das Relações Internacionais e das Políticas Públicas. 